\title{
Mechanical durability and combustion characteristics of pellets from biomass blends
}

M.V. Gil, P. Oulego, M.D. Casal, C. Pevida, J.J. Pis, F. Rubiera ${ }^{*}$

Instituto Nacional del Carbón, CSIC, Apartado 73, 33080 Oviedo, Spain

\begin{abstract}
Biofuel pellets were prepared from biomass (pine, chestnut and eucalyptus sawdust, cellulose residue, coffee husks and grape waste) and from blends of biomass with two coals (bituminous and semianthracite). Their mechanical properties and combustion behaviour were studied by means of an abrasion index and thermogravimetric analysis (TGA), respectively, in order to select the best raw materials available in the area of study for pellet production. Chestnut and pine sawdust pellets exhibited the highest durability, whereas grape waste and coffee husks pellets were the least durable. Blends of pine sawdust with $10-30 \%$ chestnut sawdust were the best for pellet production. Blends of cellulose residue and coals $(<20 \%)$ with chestnut and pine sawdusts did not decrease pellet durability. The biomass/biomass blends presented combustion profiles similar to those of the individual raw materials. The addition of coal to the biomass in low amounts did not affect the thermal characteristics of the blends.
\end{abstract}

Keywords: Biomass; Coal; Pellets; Abrasion index; Combustibility; DTG

\footnotetext{
* Corresponding author. Tel.: +34 985118 975; Fax: +34 985297662

E-mail address: frubiera@incar.csic.es (F. Rubiera)
} 


\section{Introduction}

Recently there has been increasing interest in processes for producing biofuel pellets both for domestic and industrial use. The production of such pellets has grown rapidly in Europe, Northern America and China in the last few years (Peksa-Blanchard et al., 2007; Samuelsson et al., 2009). At the same time, the need to improve the quality of the pellets has become increasingly important.

Agricultural and forest wastes as well as industrial by-products are possible materials for biofuel pellet production. Although the chemical constituents and moisture content of biomass materials vary, they all contain low amounts of polluting elements and ash (Heschel et al., 1999). For this reason, the fabrication of pellets prepared with biomass is attracting increasing interest. According to Larsson et al. (2008), pelletized biomass is rapidly becoming an important renewable source of energy production. The utilization of biomass pellets will lead to a reduction in carbon dioxide emissions, as this source of energy is considered carbon neutral, i.e., the carbon dioxide released during biomass utilisation is recycled as an integral part of the carbon cycle.

However, the combustion processes of biomass materials are complicated for three main reasons. Firstly, this fuel has a highly complex chemical and physical composition. Secondly, its combustion takes place in an uncontrolled environment and thirdly, the moisture content, density and heterogeneity of these materials have a negative effect on the efficiency of combustion. Densification of these materials would contribute to improving their behaviour as a fuel by increasing their homogeneity and allowing a wider range of lignocellulosic materials to be used as fuel (Tabarés et al., 2000).

Wang et al. (2009) have pointed out that there is a growing market for biofuels in the production of briquettes and pellets for domestic purposes, since biomass pellets can be 
used in grate furnaces and fluidized bed combustion while offering advantages, such as easy storage and transport, lower pollution, lower dust levels and higher heating values. Furthermore, the pellets offer the same advantages for automation and optimization as the petroleum-derived fuels, but with a higher combustion efficiency and a lower amount of combustion residues (Rhén et al., 2007).

Although the combustion characteristics of biomass may vary considerably depending on the composition of the raw material, the use of biomass/coal blends could produce fuel pellets with more suitable characteristics for combustion in industrial furnaces, since coal has a higher carbon content and calorific value than biomass (Heschel et al., 1999).

However, the use of different raw materials may have opposite effects on the final densified product. Pellet quality is usually measured by means of bulk density and pellet durability. Mechanical durability is a parameter that is defined by the Technical Specification CEN/TS 14588:2003, as the ability of densified biofuels to remain intact when handled, whereas durability refers to the amount of fines that are recovered from pellets after these have been subjected to mechanical or pneumatic agitation (Lehtikangas, 2001; Thomas and van der Poel, 1996). The requirements and methods used for testing the mechanical durability of pellets are defined in the technical specification CEN/TS 15210-1:2005. Low mechanical resistance leads to high dust emissions, feeding problems in boilers, and an increased risk of fire and explosions during pellet handling, storage and transport (Temmerman et al., 2006).

The published research about biofuel pellets is mainly focused on the study of the factors affecting their mechanical durability (Bergström et al., 2008; Kaliyan and Morey, 2009; Samuelsson et al., 2009). However, few studies have been conducted in 
order to compare different types of biomass for pellet fabrication, and the main raw material for these kind of studies are wood residues. On the other hand, the combustion behaviour of blends of biomass and biomass and coal for pellet production has been scarcely studied (Heschel et al., 1999; Rhén et al., 2007). Furthermore, the heterogeneity of the raw materials used in pellet and briquette production, as well as the different processes used for biomass densification, makes it difficult to generalize from the published results and necessitates an individual study for each specific situation. The primary objective of this work was to find a rapid way of selecting the best raw materials from those available in the area of study (i.e., Asturias, in NW Spain), in order to produce biofuel pellets for industrial purposes. The experiments were designed to evaluate the effect of different initial biomass materials, biomass/biomass blends and coal/biomass blends on the mechanical durability and thermal characteristics of the biofuel pellets.

\section{Materials and methods}

\subsection{Materials}

The types of biomass used in this work were pine sawdust (PIN), chestnut sawdust (CHE), eucalyptus sawdust (EUC), cellulose residue (CEL), coffee husks (COF) and grape waste (GRA). PIN and EUC are forest wastes that are available in large quantities in the area of study, whereas CHE is less common. CEL, COF and GRA are minority residues that could be used in low proportions in blends with other biomasses for pellet production. Two coals were also used in this work: a high-volatile bituminous coal (BCOAL) and a semianthracite (ACOAL). Ultimate and proximate analyses together with the heating values of the coal and biomass samples are presented in Table 1. 
Different mixtures of two biomasses, one biomass and one coal, as well as mixtures of three different components, were used for pellet preparation. It should be noted that the experimental design was influenced by the availability of the different raw materials in the area of study. Table 2 shows the composition of the blends employed. Pine sawdust and eucalyptus sawdust were added in high percentages to the biomass blends, whereas other types of biomass (CHE, CEL and COF) were included in lower percentages due to their scarcity. The 80PIN+20CHE blend was used in the three-component blends because of the good mechanical durability results attained with this binary blend. The two coals (BCOAL and ACOAL) were also used in small quantities to make up the blends. This was done in order to supplement the seasonal availability of biomass, to improve the heating value, and to study the possible improvement in the mechanical durability of the pellet blends.

The procedure employed was as follows. First, the raw materials were dried at a constant temperature of $35^{\circ} \mathrm{C}$ for $72 \mathrm{~h}$. The samples were then ground and sieved in order to obtain a particle size fraction below $1 \mathrm{~mm}$ for the biomass samples and below $0.212 \mathrm{~mm}$ for the coals. Particle sizes higher than $1 \mathrm{~mm}$ will act as predetermined breaking points in the pellets (Franke and Rey, 2006). The different blends were prepared in appropriate proportions and, manually, thoroughly mixed in order to assure a perfect homogenization that guaranteed the effective composition of mixtures.

\subsection{Pelletizing process and pellet characterisation}

The pellets were fabricated in a TDP benchtop press unit from Tabletpress.net equipped with a single punch and die set. The biomasses, biomass/biomass and biomass/coal blends were pressed into cylindrical pellets of diameter $8.0 \mathrm{~mm}$. In order to evaluate the 
durability or mechanical resistance of the pellets, a procedure usually used to evaluate the mechanical strength of coke (MICUM test) was adapted for this study (Pis et al., 1988). Samples of 40 pellets were introduced in a rotating drum with an internal diameter of $130 \mathrm{~mm}$ and a depth of $110 \mathrm{~mm}$. The drum was equipped with two opposite inner baffles $(30 \times 110 \mathrm{~mm})$ arranged perpendicular to the cylinder wall. The rotation speed was set at $35 \mathrm{rpm}$. Each pellet sample was analysed after 3000 revolutions. After being removed from the drum, the sample material was screened using a $2 \mathrm{~mm}$ sieve. Particles smaller than $2 \mathrm{~mm}$ were then weighed. The abrasion index, $I_{a}$, was obtained by means of the MICUM test from the mean value of three replications. It was calculated as the mass percentage of pellets below $2 \mathrm{~mm}$ relative to the total initial sample mass after 3000 revolutions in the rotary drum. It is considered that the lower the $I_{a}$ is, the better the quality of the pellet.

Thermal characterization of the raw materials and blends was carried out by thermogravimetric analysis (TG) and derivative thermogravimetry (DTG). Thermogravimetric analysis (TGA) is one of the most common techniques available for rapidly investigating and comparing thermal events and kinetics during the combustion and pyrolysis of solid raw materials, such as coal and biomass (Arenillas et al., 1999; Gil et al., 2010; Nowakowski et al., 2008; Pis et al., 1996; Rubiera et al., 1997; Rubiera et al., 2002).

Non-isothermal TGA was performed using a Setaram TAG24 analyser. The analyses were conducted under a $50 \mathrm{~cm}^{3} \mathrm{~min}^{-1}$ air flow at a heating rate of $15^{\circ} \mathrm{C} \mathrm{min}{ }^{-1}$ from room temperature to $1000{ }^{\circ} \mathrm{C}$. Approximately $5 \mathrm{mg}$ of sample was used for each experiment. Only a small amount of sample and slow heating rate were used in order to avoid heat 
transfer limitations. The derivative curves (DTG) of the samples were represented as a function of temperature.

\section{Results and discussion}

\subsection{Characteristics of raw materials}

As can be observed in Table 1, the samples of sawdust (PIN, CHE and EUC), which came from forest wastes, had a very low ash content $(<0.5 \%)$, whereas the minority residues (CEL, COF and GRA) and the BCOAL coal had slightly higher ash contents $(1-8 \%)$. The biomasses had a very low sulphur content $(<0.2 \%)$. All of these characteristics favour clean combustion conditions (Vamvuka et al, 2003). The semianthracite (ACOAL) presented the highest ash content (25.5\%), whereas BCOAL had the highest sulphur content (1.5\%).

In comparison with the coals, the biomasses contained a higher proportion of oxygen and hydrogen but less carbon (Table 1). These characteristics reduce their heating value since the energy contained in carbon-oxygen and carbon-hydrogen bonds is lower than that of carbon-carbon bonds (Munir et al, 2009). However, the higher oxygen content in the biomass indicates that this will have a higher thermal reactivity than the coals (Haykiri-Acma and Yaman, 2008).

The high heating value (HHV) on dry basis was found to be similar for the different types of biomass (18-22 $\mathrm{MJ} \mathrm{kg}^{-1}$ ). The coals presented higher HHV values (26-32 MJ $\mathrm{kg}^{-1}$ ), which indicated that they would be the most appropriate additives for improving the combustion characteristics of biomass. 


\subsection{Abrasion index}

Fig. 1 shows the results of the abrasion index, $I_{a}$, for all the pellets from the raw materials used in the study. The mechanical durability of the pellets was observed to decrease in the following order: $\mathrm{CHE}>\mathrm{PIN}>\mathrm{BCOAL}>\mathrm{CEL}>\mathrm{EUC}>\mathrm{COF}>\mathrm{GRA}>$ ACOAL. The pellets formed from chestnut sawdust showed the highest mechanical durability $\left(I_{a}=7 \%\right)$, followed by those made with pine sawdust $\left(I_{a}=12 \%\right)$, whose abrasion indices were very low. The pellets from cellulose residue $\left(I_{a}=29 \%\right)$ and eucalyptus sawdust $\left(I_{a}=64 \%\right)$ showed higher abrasion indices. The values obtained for the pellets from coffee husks and grape waste indicated that their durability would be very poor $\left(I_{a}>90 \%\right)$. In the case of grape waste, the sample was almost totally destroyed during the abrasion test $\left(I_{a}=99 \%\right)$ and therefore it was eliminated from further experiments. The pellets from BCOAL presented an intermediate abrasion index value $\left(I_{a}=23 \%\right)$, while that of the ACOAL pellets was $100 \%$, indicating that these pellets had been totally destroyed during the test.

The new European standard for solid biofuels "Fuel specifications and classes CEN/TS $14961: 2005 "$ is at present a classification standard, but general quality standards are about to be introduced (Ståhl and Wikström, 2009). On the basis of the relative results obtained for all the samples used in these experiments, an abrasion index of around $15 \%$ was established as the maximum value for choosing the best biomasses and blends in this study. According to this standard, the biomasses that generated the most resistant pellets were chestnut and pine. These biomasses, therefore, would be the most suitable raw materials for pellet production.

Fig. 2 shows the results of the abrasion index, $I_{a}$, for all the pellets formed from blends of two biomasses (Fig. 2a), blends of three components (Fig. 2b) and blends of biomass 
and coal (Fig. 2c and 2d). The pellets from the PIN+CHE blends all exhibited a similar mechanical durability, since the abrasion index values for the PIN and CHE pellets were very close (Fig. 2a). These values were very low for these samples, indicating that the pine sawdust and chestnut sawdust blend would be suitable in the right proportions (10$30 \%$ of chestnut sawdust) for pellet production. Moreover, it was found that the addition of chestnut sawdust improved the mechanical durability of the pellets formed from pine sawdust, despite the low abrasion index of PIN.

Although the pellets from the PIN + CHE blends showed similar mechanical durability, the lowest abrasion index value was obtained with pellets formed from the 80PIN+20CHE blend (8\%), and this mixture was later used to make the three component blends. Thus, this sample was blended with a small percentage $(5 \%)$ of CEL, COF and ACOAL, but all three cases, the abrasion index of the pellets formed using ternary blends was found to be higher than that obtained with a the binary blend (Fig. 2b). It can therefore be concluded that the addition of the third component did not improve mechanical durability, since no synergetic behaviour was observed between the components. However, when a low percentage $(5 \%)$ of CEL or ACOAL was added as third component, the abrasion index only slightly increased, indicating that ternary mixtures could be used without significantly affecting the mechanical durability of the pellets. Thus, pellet fabrication offers the possibility of recycling minority wastes as an alternative to less environmentally friendly ways of disposal.

When the pine was blended with eucalyptus (PIN+EUC), the abrasion index decreased proportionally as the proportion of pine increased up to $40 \%$, whereas if the pine percentage was kept to between $40 \%$ and $70 \%$, mechanical durability remained more or less constant, its values being slightly higher than those of pine pellets (Fig. 2a). Thus, 
the addition of pine sawdust in a proportion equal to or higher than $40 \%$ would be necessary to produce pellets from eucalyptus sawdust in order to see a reduction in the abrasion index of eucalyptus pellets. The resultant durability, however, would not be very satisfactory.

In the case of the chestnut and eucalyptus mixture (EUC+CHE), chestnut sawdust was only added in proportions of up to $20 \%$, since this material is available in low quantities in the area of study. However, although the mechanical durability of eucalyptus pellets was improved when chestnut was added (Fig. 2a), the abrasion index was found to be extremely high. This blend therefore was considered unsuitable for pellet production.

Finally, a mixture of pine sawdust with a small percentage of cellulose residue (PIN+CEL) was assayed. The results indicated that the addition of CEL in a percentage equal to or lower than $20 \%$ did not modify the abrasion index of the pine pellets (Fig. 2a). Thus, these blends could be employed for pellet fabrication and the cellulose residue waste could be reused.

The pellets from blends BCOAL+PIN and BCOAL+CHE displayed a similar mechanical durability when BCOAL was added to the mixture in a proportion of $5-20 \%$ (Fig. 2c). Their abrasion index values were found to be very low and similar to those of the raw biomasses, suggesting that a blend of pine sawdust or chestnut sawdust with percentages of BCOAL of up to $20 \%$ would be highly suitable for pellet production. The blend of BCOAL with eucalyptus sawdust (BCOAL+EUC) considerably improved the mechanical durability of the eucalyptus pellets when the coal was added in a percentage equal to, or higher than, $10 \%$ (Fig. 2c). However, the abrasion indices could then become excessively high due to the already high values of the BCOAL pellets. 
In contrast, when pine sawdust was blended with ACOAL (ACOAL+PIN), pine pellet durability was not affected if only $5 \%$ of coal was added, whereas it increased slightly when the percentage of coal added was $10-15 \%$ (Fig. 2d), there being a dramatic increase when additions reached 20\%. When chestnut sawdust was blended with ACOAL (ACOAL $+\mathrm{CHE}$ ), chestnut pellet durability was not affected if coal addition remained inside the proportion of $5-15 \%$, whereas it increased slightly when the percentage of coal added reached 20\% (Fig. 2d). Therefore blending ACOAL with chestnut sawdust in a proportion of $5-15 \%$ would best suit the purpose of producing pellets.

\subsection{Thermal characteristics}

To evaluate the effect of the amount and the type of raw material (biomass and coal) on the combustion process, the blends were subjected to thermogravimetric analysis under an oxidizing atmosphere. In the case of the blends, the thermal analysis was carried out only on those blends that presented the best abrasion index values, i.e., the best mechanical durability. The DTG curves for the biomass and coal samples and their blends, under air atmosphere, are shown in Figs. 4-6.

\subsubsection{Combustion behaviour of individual biomasses and coal pellets}

Fig. 3 shows the DTG combustion profiles for the pellets formed from each individual biomass and both coal samples. In Fig. 3, the DTG profile extends over the entire temperature interval $\left(25-700^{\circ} \mathrm{C}\right)$ within which the thermogravimetric analysis was conducted. From the curves, it can be seen that an initial mass loss (stage A) occurred between the temperatures of $25^{\circ} \mathrm{C}$ and $105^{\circ} \mathrm{C}$ for all samples, due to moisture loss. In 
this range, the biomass samples experienced two-step mass losses (stages B and C), compared to only a one-step mass loss (stage C) for the coal samples.

In the case of the biomass samples, the mass loss in stage $B$, where the main mass loss occurred, is due to oxidative degradation -i.e., volatiles are released and then burned-, whereas the mass loss in stage $\mathrm{C}$ is due to the combustion of the remaining char. Haykırı-Açma (2003) described the first stage as the burning region in which volatiles are released and burned. Zheng and Koziński (2000) claimed that biomass combustion consisted of two main steps, the first one characterised by the devolatilization process and burning of light organic volatiles and the second mass loss resulting from the oxidation of char.

The combustion temperature interval, mass loss, the final residue after combustion, the peak temperature and the maximum rate of mass loss (DTGmax) corresponding to the two different stages of mass loss (stages B and C) are presented in Table 3. The initial temperature in stage $\mathrm{B}$ and the final temperature in stage $\mathrm{C}$ were considered as the temperature values at which the rate of mass loss was $0.005 \% / \mathrm{s}$ (Rubiera et al., 1999). The combustion of coal started at a higher temperature $\left(312^{\circ} \mathrm{C}\right.$ for BCOAL and $451^{\circ} \mathrm{C}$ for ACOAL) than that of the biomass samples $\left(142-212^{\circ} \mathrm{C}\right)$. Furthermore, the coal samples had a lower rate of mass loss (DTGmax), $0.206 \% \mathrm{~s}^{-1}$ for BCOAL and $0.332 \%$ $\mathrm{s}^{-1}$ for ACOAL, compared to the biomass samples (except for the COF sample) in stage B, $0.385-0.441 \% \mathrm{~s}^{-1}$.

Coal combustion was probably dominated by the oxidation of char, while, in the case of the biomass samples, it was dominated by the oxidation of the volatile matter, which was present in a large proportion, i.e. approximately $80 \%$. This caused the biomass to burn at very low temperatures. 
The pellets formed from COF generated more unburned residual material $(4.7 \%)$ at the end of the experiment than the other biomass samples, in accordance with the higher ash content of the raw material (Table 1). However, pellets made with PIN generated the lowest amount of unburned residue (0.6 \%). Likewise, Tabarés et al. (2000) found that briquettes made with pine and eucalyptus generated the lowest amount of unburned material in their combustion experiments.

In order to ensure a combination of efficiency and comfort for the consumer of pellets in the domestic heating sector, it is necessary to avoid a high ash content, as this would remove the need to empty the ash box at regular interval, minimize the danger of slag formation in the boiler and reduce soot emissions (Obernberger and Thek, 2004). In view of these risks, the forest sawdust samples would appear to be the most suitable raw materials for pellet production.

Taking into consideration that the temperature value at the maximum rate of mass loss is considered inversely proportional to reactivity (Haykır1-Açma, 2003), the coals proved to be the least reactive materials, ACOAL being less reactive than BCOAL. In stage $\mathrm{B}$, the COF pellets were found to be the most reactive compared to the other biomass samples. The COF pellets were also the most reactive biomass samples in stage $\mathrm{C}$, the CEL pellets being the least reactive. It should also be noted that the peak temperature in stage $\mathrm{C}$ for the CEL sample is higher than that of the other biomass samples and very close to that of the coals (Fig. 3).

On the other hand, the COF sample exhibited the lowest DTGmax in stage B, $0.154 \%$ $\mathrm{s}^{-1}$, and the highest DTGmax in stage C, $0.219 \% \mathrm{~s}^{-1}$, compared to the other biomass samples. This shows that the volatile matter in the COF sample burned at a lower rate and for a longer time than that in the other biomass samples, whereas char combustion 
proceeded at a higher rate and at a lower temperature. in short the behaviour of COF was different to that of the other biomass samples. This is in agreement with Rhén et al. (2007), who claim that the char yield and char combustion rate of a biofuel are correlated to the chemical composition of the biomass.

\subsubsection{Combustion behaviour of pellets formed from blends of raw materials}

The DTG combustion profiles corresponding to the pellets formed from biomass/biomass binary blends, under air atmosphere, are shown in Fig. 4. The DTG curves corresponding to the pellets formed from the blends of three components are represented in Fig. 5. Fig. 6 shows the DTG profiles corresponding to the pellets from the biomass/coal blends. DTG curves are only shown in the temperature range where sample combustion occurs, because at lower temperatures there is only a minor initial mass loss due to the loss of moisture in all the samples.

Fig. 4 shows the DTG combustion profiles for the pellets formed from binary blends of two biomass samples. The biomass/biomass blends displayed combustion profiles situated approximately halfway between those of the individual raw materials. Table 4 presents the combustion temperature interval, the mass loss, the final residue after combustion, the peak temperature and the maximum rate of mass loss (DTGmax) corresponding to the two different stages of mass loss (stages B and C) for the pellets formed from PIN+CHE, PIN+EUC, EUC+CHE and PIN+CEL.

All these pellets from binary blends displayed similar temperature intervals of combustion to each other (Table 4), for stages B and C, as well as similar intervals to those of the individual materials of each mixture (Fig. 4). Similarly, the biomass/biomass blends all displayed similar mass loss and residue values (Table 4), for 
stages $\mathrm{B}$ and $\mathrm{C}$, as well as similar values to those of the individual raw materials. In the case of the 90PIN+10CEL blend, the mass loss and residue values of the raw materials were very different. However, the mass loss and residue values were also similar to those of the PIN sample, the largest component in the blend.

The binary blends also had similar peak temperatures (Table 4) to each other and to those of the individual materials, in both combustion stages, except for the 90PIN+10CEL sample in stage $\mathrm{C}$, which had a value very close to that of the PIN sample (Fig. 4d), PIN being the largest component in the mixture. The maximum rates of mass loss for the binary blends occupy an intermediate position among the raw materials (Table 4), the DTGmax value of the 90PIN+10CEL sample in stage C being very close to that of the PIN sample (Fig. 4d).

These results indicate that the thermal characteristics of the pellets formed from the biomass blends did not differ from those of the individual biomasses which made up the mixture. Only the PIN+CEL blend may have been affected by the presence of CEL, but as CEL was present in such a low amount, the thermal characteristics of the blend were no different to those of the PIN pellets. Therefore, in this study, the choice of raw materials for pellet production should not be influenced by the thermal characteristics of the pellets.

Fig. 5 shows the DTG combustion profiles for the pellets from the blends of three components. These blends also had combustion profiles that occupy an intermediate position among those of the individual raw materials, although in this case, they were more similar to that of the $80 \mathrm{PIN}+20 \mathrm{CHE}$ blend. Table 5 contains the combustion temperature interval, the mass loss, the final residue after combustion, the peak temperature and the maximum rate of mass loss (DTGmax) corresponding to the two 
different stages of mass loss (stages $B$ and $C$ ) for the pellets from the $5 \mathrm{CEL}+95(80 \mathrm{PIN}+20 \mathrm{CHE}), \quad 5 \mathrm{COF}+95(80 \mathrm{PIN}+20 \mathrm{CHE}) \quad$ and 5ACOAL+95(80PIN+20CHE) blends. The ternary blends showed temperature intervals of combustion, mass loss, residue, peak temperatures and DTGmax values (Table 5), in stages $\mathrm{B}$ and $\mathrm{C}$, that were similar to those of the $80 \mathrm{PIN}+20 \mathrm{CHE}$ blend, the principal component of the mixture (Fig. 5).

Fig. 6 shows the DTG combustion profiles for the pellets formed from blends of the biomass and coal samples. The biomass/coal blends also presented combustion profiles in between those of the individual raw materials. All the biomass/coal blends showed two combustion peaks, both of which were situated close to those of the biomass sample, the second peak being slightly broader at higher temperatures due to the influence of the coal. Table 6 contains the combustion temperature interval, the mass loss, the final residue after combustion, the peak temperature and the maximum rate of mass loss (DTGmax) corresponding to the two different stages of mass loss (stages B and C) for the pellets from the 20BCOAL+80PIN, 20BCOAL+80CHE, 20BCOAL+80EUC, 5ACOAL+95PIN and 5ACOAL+95CHE blends. The temperature intervals of combustion for the biomass/coal blends in stage B (Table 6) were similar to those of the biomass sample. However in stage $C$, although they started at approximately the same temperature as that of the biomass sample they finished at slightly higher temperatures, as previously mentioned (Fig. 6). The mass loss values for the biomass/coal blends in stage B (Table 6) were slightly lower than those of the biomass. However, their values, as well as the residue percentages, were higher in stage C, due to the effect of coal. Obernberger and Thek (2004) stated that a higher ash content in the pellets might be acceptable if the pellets are destined for industrial use 
due to the greater robustness and sophistication of industrial combustion systems compared to domestic heating systems. Therefore, the pellets formed from blends of biomass and coal, which had higher values of residue content than the other samples, should be reserved for industrial use in large furnaces.

The peak temperatures of the biomass/coal blends in stage B (Table 6) were similar to those of the biomass samples, whereas the corresponding DTGmax values were lower than those of the biomass. In stage $\mathrm{C}$, the peak temperatures of the biomass/coal blends (Table 6) were slightly higher than those of the biomass samples, whereas the DTGmax values, although close to those of the biomass samples, were far from those of the coal samples (Fig. 6).

Thus, the thermogravimetric characteristics of the biomass/coal blends differed only slightly in relation to the individual biomasses due to the presence of coal in the mixture. Only the residue values and the final combustion temperature showed slight increases. Thus, it can be concluded that the addition of coal in small amounts will not affect the combustion characteristics of the pellets.

In view of the results obtained, further studies on pellet combustion in a small-scale combustor are being planned in order to extend our knowledge of the combustion behaviour of pellets before they are produced at industrial scale. The selected raw materials, i.e., those with the best mechanical durability, will be first used for pellet production in a pilot-scale pellet press.

\section{Conclusions}

The most durable pellets were found with: chestnut sawdust (CHE), pine sawdust (PIN), CHE+PIN $(\leq 30 \%$ CHE), cellulose residue $(\mathrm{CEL})+\mathrm{PIN}(\leq 20 \% \mathrm{CEL})$ and 
$5 \% \mathrm{CEL}+(80 \% \mathrm{PIN}+20 \% \mathrm{CHE})$. A bituminous coal (BCOAL) and a semianthracite

(ACOAL) could be added to biomass for pellet production in the following proportions:

$\mathrm{CHE}+\mathrm{BCOAL} \quad(\leq 20 \% \quad \mathrm{BCOAL}), \quad \mathrm{PIN}+\mathrm{ACOAL} \quad(\leq \quad 15 \% \quad \mathrm{ACOAL}) \quad$ and $5 \% \mathrm{ACOAL}+(80 \% \mathrm{PIN}+20 \% \mathrm{CHE})$.

The addition of coal in low percentages to the blends with biomass did not modify the combustion behaviour of the biomass. The thermal behaviour of the pellets made up of two different biomasses was similar to those of the individual components.

\section{Acknowledgements}

Work carried out with financial support from the Spanish MICINN (Project PS120000-2006-3, ECOCOMBOS), and co-financed by the European Regional Development Fund, ERDF.

\section{References}

Arenillas, A., Rubiera, F., Pis, J.J., Jones, J.M., Williams, A., 1999. The effect of the textural properties of bituminous coal chars on NO emissions. Fuel 78, 1779-1785.

Bergström, D., Israelsson, S., Öhman, M., Dahlqvist, S.A., Gref, R., Boman, C., Wästerlund, I., 2008. Effects of raw material particle size distribution on the characteristics of Scots pine sawdust fuel pellets. Fuel Process. Technol. 89, 13241329.

Franke, M., Rey, A., 2006. Pelleting quality. World Grain 2006 May, pp. 78-79.

Gil, M.V., Casal, D., Pevida, C., Pis, J.J., Rubiera F., 2010. Thermal behaviour and kinetics of coal/biomass blends during co-combustion. Bioresource Technol. 101, 5601-5608.

Haykırı-Açma, H., 2003. Combustion characteristics of different biomass materials. Energ. Convers. Manage. 44, 155-162.

Haykiri-Acma, H., Yaman, S., 2008. Effect of co-combustion on the burnout of lignite/biomasa blends: A Turkish case study. Waste Manage. 28, 2077-2084.

Heschel, W., Rweyemamu, L., Scheibner, T., Meyer, B., 1999. Abatement of emissions in small-scale combustors through utilisation of blended pellet fuels. Fuel Process. Technol. 61, 223-242.

Kaliyan, N., Morey, V., 2009. Factors affecting strength and durability of densified biomass products. Biomass Bioenerg. 33, 337-359. 
Larsson, S.H., Thyrel, M., Geladi, P., Lestander, T.A., 2008. High quality biofuel pellet production from pre-compacted low density raw materials. Bioresource Technol. 99, 7176-7182.

Lehtikangas, P., 2001. Quality properties of pelletised sawdust, logging residues and bark. Biomass Bioenerg. 20, 351-360.

Munir, S., Daood, S.S., Nimmo, W., Cunliffe, A.M., Gibbs, B.M., 2009. Thermal analysis and devolatilization kinetics of cotton stalk, sugar cane bagasse and shea meal under nitrogen and air atmospheres. Bioresource Technol. 100, 1413-1418.

Nowakowski, D.J., Woodbridge, C.R., Jones, J.M., 2008. Phosporus catalysis in the pyrolysis behaviour of biomass. J. Anal. Applied Pyrol. 87, 197-204.

Obernberger, I., Thek, G., 2004. Physical characterisation and chemical composition of densified biomass fuels with regard to their combustion behaviour. Biomass Bioenerg. 27, 653-669.

Peksa-Blauchard, M., Dolzan, P., Grassi, A., Heinimö, J., Junginger, M., Ranta, T., Walter, A., 2007. Global Wood Pellets Markets and Industry: Policy Drivers, Market Status and Raw Material Potential. IEA Bioenergy Task 40, November 2007.

Pis, J.J., Cagigas, A., Simon, P., Lorenzana, J.J., 1988. Effect of aerial oxidation of coking coals on the technological properties of the resulting cokes. Fuel Process. Technol. 20, 307-316.

Pis, J.J., de la Puente, G., Fuente, E., Moran, A., Rubiera, F., 1996. A study of the selfheating of fresh and oxidized coals by differential thermal analysis. Thermochim. Acta 279, 93-101.

Rhén, C., Öhman, M., Gref, R., Wästerlund, I., 2007. Effect of raw material composition in woody biomass pellets on combustion characteristics. Biomass Bioenerg. 31, 66-72.

Rubiera, F., Arenillas, A., Arias, B., Pis, J.J., 2002. Modification of combustion behaviour and NO emissions by coal blending. Fuel Process. Technol. 77-78, 111117.

Rubiera, F., Arenillas, A., Fuente, E., Miles, N., Pis, J.J., 1999. Effect of the grinding behaviour of coal blends on coal utilisation for combustion. Powder Technol. 105, 351-356.

Rubiera, F., Morán, A., Martínez, O., Fuente, E., Pis, J.J., 1997. Influence of biological desulphurisation on coal combustion performance. Fuel Process. Technol. 52, 165173.

Samuelsson, R., Thyrel, M., Sjöström, M., Lestander, T.A., 2009. Effect of biomaterial characteristics on pelletizing properties and biofuel pellet quality. Fuel Process. Technol. 90, 1129-1134.

Ståhl, M., Wikström, F., 2009. Swedish perspective on wood fuel pellets for household heating: A modified standard for pellets could reduce end-user problems. Biomass Bioenerg. 33, 803-809.

Tabarés, J.L.M., Ortiz, L., Granada, E., Viar, F.P., 2000. Feasibility study of energy use for densificated lignocellulosic material (briquettes). Fuel 79, 1229-1237.

Temmerman, M., Rabier, F., Jensen, P.D., 2006. Comparative study of durability test methods for pellets and briquettes. Biomass Bioenerg. 30, 964-972.

Thomas, M., van der Poe1, A.F.B., 1996. Physical quality of pelleted animal feed. 1. Criteria for pellet quality. Anim. Feed Sci. Tech. 61, 89-112.

Vamvuka, D., Pasadakis, N., Kastanaki, E., Grammelis, P., Kakaras, E., 2003. Kinetic modeling of coal/agricultural by-product blends. Energ. Fuel 17, 549-558. 
Wang, C., Wang, F., Yang, Q., Liang, R., 2009. Thermogravimetric studies of the behavior of wheat straw with added coal during combustion. Biomass Bioenerg. 33, 50-56.

Zheng, J.A., Koziński, J.A., 2000. Thermal events occurring during the combustion of biomass residue. Fuel 79, 181-192. 


\section{Figure captions}

Fig. 1. Abrasion index for pellets formed from individual materials used in this study.

Fig. 2. Abrasion index for pellets formed from blends of two biomasses (a), blends of three components (b), blends of biomass and BCOAL (c) and blends of biomass and $\operatorname{ACOAL}(d)$.

Fig. 3. DTG curves for pellets formed from raw materials in an air flow of $50 \mathrm{~cm}^{3} \mathrm{~min}^{-1}$, at a heating rate of $15^{\circ} \mathrm{C} \mathrm{min}^{-1}$.

Fig. 4. DTG curves for pellets formed from blends of two biomasses in an air flow of 50 $\mathrm{cm}^{3} \min ^{-1}$, at a heating rate of $15^{\circ} \mathrm{C} \min ^{-1}$ : (a) PIN+CHE, (b) PIN+EUC, (c) EUC+CHE and (d) PIN+CEL.

Fig. 5. DTG curves for pellets formed from blends of three components in an air flow of $50 \mathrm{~cm}^{3} \mathrm{~min}^{-1}$, at a heating rate of $15^{\circ} \mathrm{C} \mathrm{min}^{-1}$ : (a) $\mathrm{CEL}+(80 \mathrm{PIN}+20 \mathrm{CHE})$, (b) $\mathrm{COF}+(80 \mathrm{PIN}+20 \mathrm{CHE})$ and (c) ACOAL $+(80 \mathrm{PIN}+20 \mathrm{CHE})$.

Fig. 6. DTG curves for pellets formed from blends of biomass and coal in an air flow of $50 \mathrm{~cm}^{3} \mathrm{~min}^{-1}$, at a heating rate of $15^{\circ} \mathrm{C} \mathrm{min}^{-1}$ : (a) BCOAL+PIN, (b) BCOAL+EUC, (c) BOAL+EUC, (d) ACOAL+PIN and (e) ACOAL+CHE. 
Table 1

Ultimate and proximate analyses, and high heating values of the raw materials

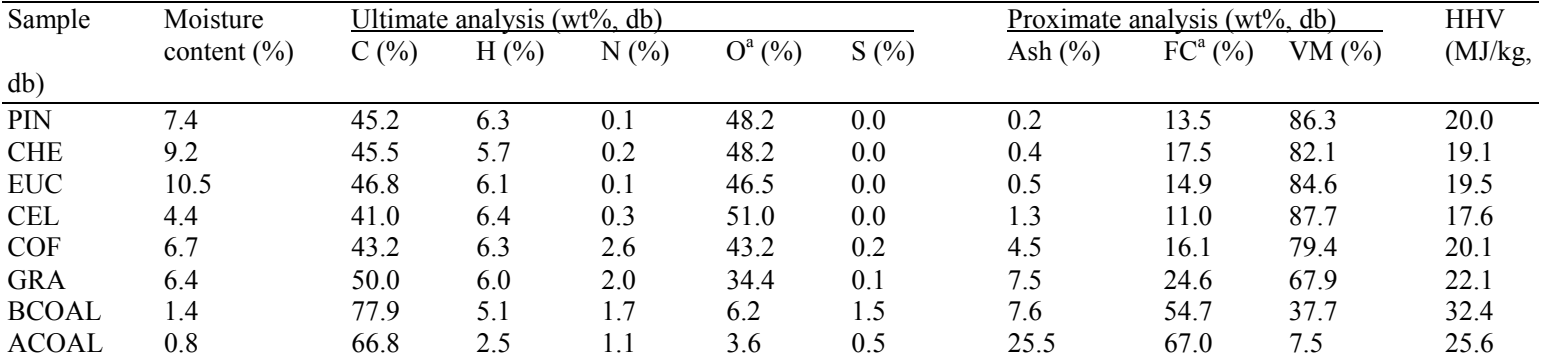

${ }^{\mathrm{a}}$ Calculated by difference; db: dry basis 
Table 2

Composition of the blends used for pellet preparation

\begin{tabular}{|c|c|c|c|}
\hline \multicolumn{4}{|c|}{ Blends of two biomasses } \\
\hline$\%$ Pine $+\%$ Chesnut & $\%$ Pine $+\%$ Eucaliptus & $\%$ Eucaliptus $+\%$ Chesnut & $\%$ Pine $+\%$ Cellulose residue \\
\hline 90PIN+10CHE & 70PIN+30EUC & \multirow[t]{2}{*}{$80 \mathrm{EUC}+20 \mathrm{CHE}$} & $90 \mathrm{PIN}+10 \mathrm{CEL}$ \\
\hline $85 \mathrm{PIN}+15 \mathrm{CHE}$ & $60 \mathrm{PIN}+40 \mathrm{EUC}$ & & $80 \mathrm{PIN}+20 \mathrm{CEL}$ \\
\hline 80PIN+20CHE & $50 \mathrm{PIN}+50 \mathrm{EUC}$ & & \\
\hline $75 \mathrm{PIN}+25 \mathrm{CHE}$ & $40 \mathrm{PIN}+60 \mathrm{EUC}$ & & \\
\hline 70PIN+30CHE & $30 \mathrm{PIN}+70 \mathrm{EUC}$ & & \\
\hline \multicolumn{4}{|c|}{ Blends of biomass and coal } \\
\hline$\%$ Bituminous coal $+\%$ Pine & \multicolumn{2}{|c|}{$\%$ Bituminous coal $+\%$ Chesnut } & $\%$ Bituminous coal $+\%$ Eucaliptus \\
\hline 5BCOAL+95PIN & \multicolumn{2}{|c|}{$5 \mathrm{BCOAL}+95 \mathrm{CHE}$} & $5 \mathrm{BCOAL}+95 \mathrm{EUC}$ \\
\hline 10BCOAL+90PIN & \multicolumn{2}{|c|}{ 10BCOAL+90CHE } & 10BCOAL+90EUC \\
\hline $15 \mathrm{BCOAL}+85 \mathrm{PIN}$ & & \\
\hline $20 \mathrm{BCOAL}+80 \mathrm{PIN}$ & \multicolumn{2}{|c|}{$\begin{array}{l}15 \mathrm{BCOAL}+85 \mathrm{CHE} \\
20 \mathrm{BCOAL}+80 \mathrm{CHE}\end{array}$} & 20BCOAL+80EUC \\
\hline \multicolumn{2}{|c|}{$\%$ Semianthracite $+\%$ Pine } & \multicolumn{2}{|c|}{$\%$ Semianthracite $+\%$ Chesnut } \\
\hline \multicolumn{2}{|c|}{$5 \mathrm{ACOAL}+95 \mathrm{PIN}$} & \multicolumn{2}{|c|}{$5 \mathrm{ACOAL}+95 \mathrm{CHE}$} \\
\hline \multicolumn{2}{|c|}{ 10ACOAL+90PIN } & \multicolumn{2}{|c|}{ 10ACOAL+90CHE } \\
\hline \multicolumn{2}{|c|}{$15 \mathrm{ACOAL}+85 \mathrm{PIN}$} & \multicolumn{2}{|c|}{$15 \mathrm{ACOAL}+85 \mathrm{CHE}$} \\
\hline \multicolumn{2}{|c|}{$20 \mathrm{ACOAL}+80 \mathrm{PIN}$} & \multicolumn{2}{|c|}{$20 \mathrm{ACOAL}+80 \mathrm{CHE}$} \\
\hline \multicolumn{4}{|c|}{ Blends of three components } \\
\hline $\begin{array}{l}\text { \% Cellulose residue + } \\
\%(80 \mathrm{PIN}+20 \mathrm{CHE})\end{array}$ & \multicolumn{2}{|c|}{$\begin{array}{c}\% \text { coffee husks }+ \\
\%(80 \mathrm{PIN}+20 \mathrm{CHE})\end{array}$} & $\begin{array}{l}\text { \% Semianthracite + } \\
\%(80 \mathrm{PIN}+20 \mathrm{CHE})\end{array}$ \\
\hline $5 \mathrm{CEL}+95(80 \mathrm{PIN}+20 \mathrm{CHE})$ & \multicolumn{2}{|c|}{$5 \mathrm{COF}+95(80 \mathrm{PIN}+20 \mathrm{CHE})$} & $5 \mathrm{ACOAL}+95(80 \mathrm{PIN}+20 \mathrm{CHE})$ \\
\hline
\end{tabular}


Table 3

Temperature interval, mass loss, residue, peak temperature and maximum rate of mass loss (DTGmax) for the combustion stages B and C for pellets from individual materials used in this study

\begin{tabular}{|c|c|c|c|c|c|c|c|c|c|}
\hline \multirow[t]{2}{*}{ Sample } & \multicolumn{2}{|c|}{ Temperature interval $\left({ }^{\circ} \mathrm{C}\right)$} & \multicolumn{2}{|c|}{ Mass loss $(\%)$} & \multirow[t]{2}{*}{ Residue (\%) } & \multicolumn{2}{|c|}{ Peak temperature $\left({ }^{\circ} \mathrm{C}\right)$} & \multicolumn{2}{|c|}{ DTGmax $(\% / \mathrm{s})$} \\
\hline & Stage B & Stage C & Stage B & Stage C & & Stage B & Stage C & Stage B & Stage C \\
\hline$\overline{\mathrm{PIN}}$ & $192-353$ & $353-490$ & 62.6 & 30.1 & 0.6 & 322 & 457 & 0.385 & 0.132 \\
\hline $\mathrm{CHE}$ & $209-360$ & $360-487$ & 64.1 & 24.3 & 1.5 & 313 & 460 & 0.441 & 0.093 \\
\hline EUC & 212-339 & $339-487$ & 64.4 & 25.4 & 1.0 & 309 & 454 & 0.473 & 0.077 \\
\hline CEL & $205-377$ & $377-537$ & 69.4 & 25.0 & 1.9 & 313 & 490 & 0.462 & 0.076 \\
\hline $\mathrm{COF}$ & $142-383$ & $383-493$ & 59.8 & 31.1 & 4.7 & 302 & 444 & 0.154 & 0.219 \\
\hline BCOAL & - & $312-600$ & - & 98.3 & 8.3 & - & 500 & - & 0.206 \\
\hline ACOAL & - & $451-673$ & - & 99.8 & 26.7 & - & 554 & - & 0.332 \\
\hline
\end{tabular}


Table 4

Temperature interval, mass loss, residue, peak temperature and maximum rate of mass loss (DTGmax) for the combustion stages B and C for pellets from blends of two biomasses

\begin{tabular}{|c|c|c|c|c|c|c|c|c|c|}
\hline \multirow[t]{2}{*}{ Sample } & \multicolumn{2}{|c|}{ Temperature interval $\left({ }^{\circ} \mathrm{C}\right)$} & \multicolumn{2}{|c|}{ Mass loss (\%) } & \multirow[t]{2}{*}{ Residue (\%) } & \multicolumn{2}{|c|}{ Peak temperature $\left({ }^{\circ} \mathrm{C}\right)$} & \multicolumn{2}{|c|}{ DTGmax $(\% / \mathrm{s})$} \\
\hline & Stage B & Stage C & Stage B & Stage C & & Stage B & Stage C & Stage B & Stage C \\
\hline 90PIN+10CHE & $192-360$ & $360-487$ & 64.2 & 28.1 & 1.2 & 315 & 457 & 0.412 & 0.132 \\
\hline 80PIN+20CHE & 192-339 & $339-490$ & 60.6 & 30.9 & 1.1 & 315 & 460 & 0.423 & 0.119 \\
\hline $70 \mathrm{PIN}+30 \mathrm{CHE}$ & $192-346$ & $346-493$ & 64.0 & 36.0 & 1.2 & 310 & 460 & 0.437 & 0.113 \\
\hline $70 \mathrm{PIN}+30 \mathrm{EUC}$ & $189-342$ & $342-484$ & 63.5 & 28.3 & 0.9 & 316 & 460 & 0.448 & 0.096 \\
\hline $50 \mathrm{PIN}+50 \mathrm{EUC}$ & $182-339$ & $339-490$ & 62.0 & 29.2 & 0.8 & 316 & 457 & 0.467 & 0.097 \\
\hline 40PIN+70EUC & 206-346 & $346-500$ & 62.5 & 28.5 & 0.9 & 312 & 457 & 0.475 & 0.092 \\
\hline $80 \mathrm{EUC}+20 \mathrm{CHE}$ & $206-339$ & $339-490$ & 61.2 & 28.7 & 0.9 & 309 & 457 & 0.453 & 0.082 \\
\hline 90PIN+10CEL & $209-346$ & $346-500$ & 62.1 & 30.9 & 0.9 & 319 & 463 & 0.430 & 0.108 \\
\hline
\end{tabular}


Table 5

Temperature interval, mass loss, residue, peak temperature and maximum rate of mass loss (DTGmax) for the combustion stages B and C for pellets from blends of three components

Sample

$$
\text { Temperature }
$$

Temperature interval $\left({ }^{\circ} \mathrm{C}\right) \quad$ Mass loss $(\%)$ Residue (\%) $\quad$ Peak temperature $\left({ }^{\circ} \mathrm{C}\right)$

DTGmax $(\% / \mathrm{s})$

5CEL+95(80PIN+20CHE) 199-356 Stage C Stage B Stage C Stage B Stage C Stage B Stage C 62.9 29.8

$0.9 \quad 311$ 467 0.429 0.106

$63.1 \quad 28.9$

$1.2 \quad 312$

$312 \quad 460$

$0.386 \quad 0.11$


Table 6

Temperature interval, mass loss, residue, peak temperature and maximum rate of mass loss (DTGmax) for the combustion stages B and C for pellets from blends of biomass and coal

\begin{tabular}{|c|c|c|c|c|c|c|c|c|c|}
\hline \multirow[t]{2}{*}{ Sample } & \multicolumn{2}{|c|}{ Temperature interval $\left({ }^{\circ} \mathrm{C}\right)$} & \multicolumn{2}{|c|}{ Mass loss (\%) } & \multirow[t]{2}{*}{ Residue (\%) } & \multicolumn{2}{|c|}{ Peak temperature $\left({ }^{\circ} \mathrm{C}\right)$} & \multicolumn{2}{|c|}{ DTGmax $(\% / \mathrm{s})$} \\
\hline & Stage B & Stage C & Stage B & Stage $\mathrm{C}$ & & Stage B & Stage $\mathrm{C}$ & Stage B & Stage $\mathrm{C}$ \\
\hline 20BCOAL+80PIN & $209-362$ & $362-583$ & 48.8 & 44.4 & 3.3 & 322 & 474 & 0.307 & 0.104 \\
\hline 20BCOAL+80CHE & 199-349 & $349-560$ & 51.6 & 40.5 & 2.7 & 302 & 474 & 0.285 & 0.083 \\
\hline $20 \mathrm{BCOAL}+80 \mathrm{EUC}$ & $216-342$ & $342-523$ & 61.1 & 31.0 & 2.3 & 312 & 464 & 0.446 & 0.091 \\
\hline$\overline{5 \mathrm{ACOAL}+95 \mathrm{PIN}}$ & $210-361$ & $361-501$ & 61.2 & 29.8 & 2.5 & 327 & 468 & 0.367 & 0.105 \\
\hline$\overline{5 \mathrm{ACOAL}+95 \mathrm{CHE}}$ & $199-363$ & $363-533$ & 57.8 & 31.7 & 2.7 & 304 & 471 & 0.332 & 0.086 \\
\hline
\end{tabular}




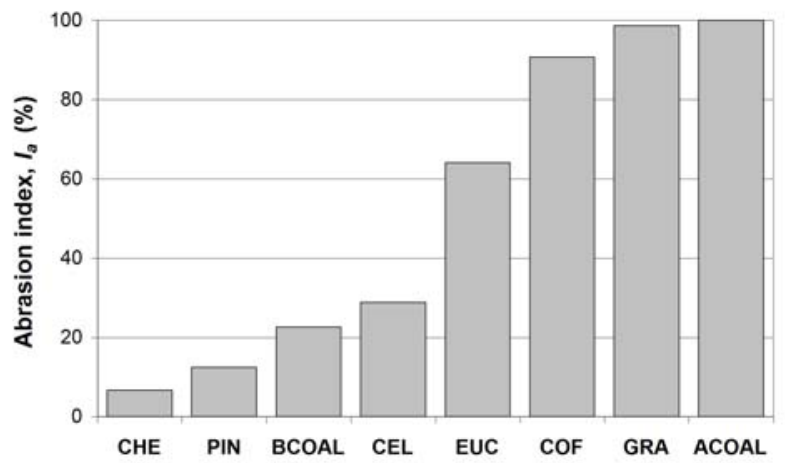

Fig. 1. 

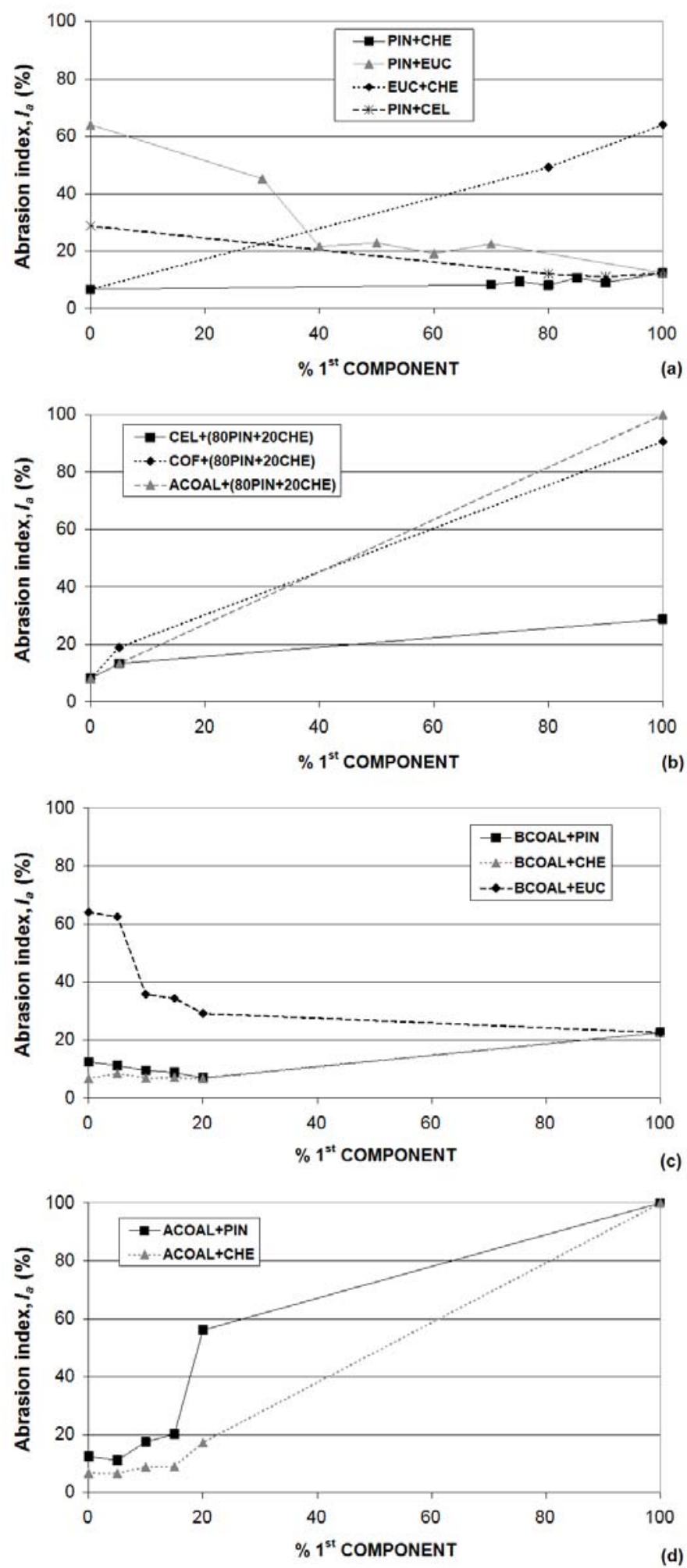

Fig. 2. 


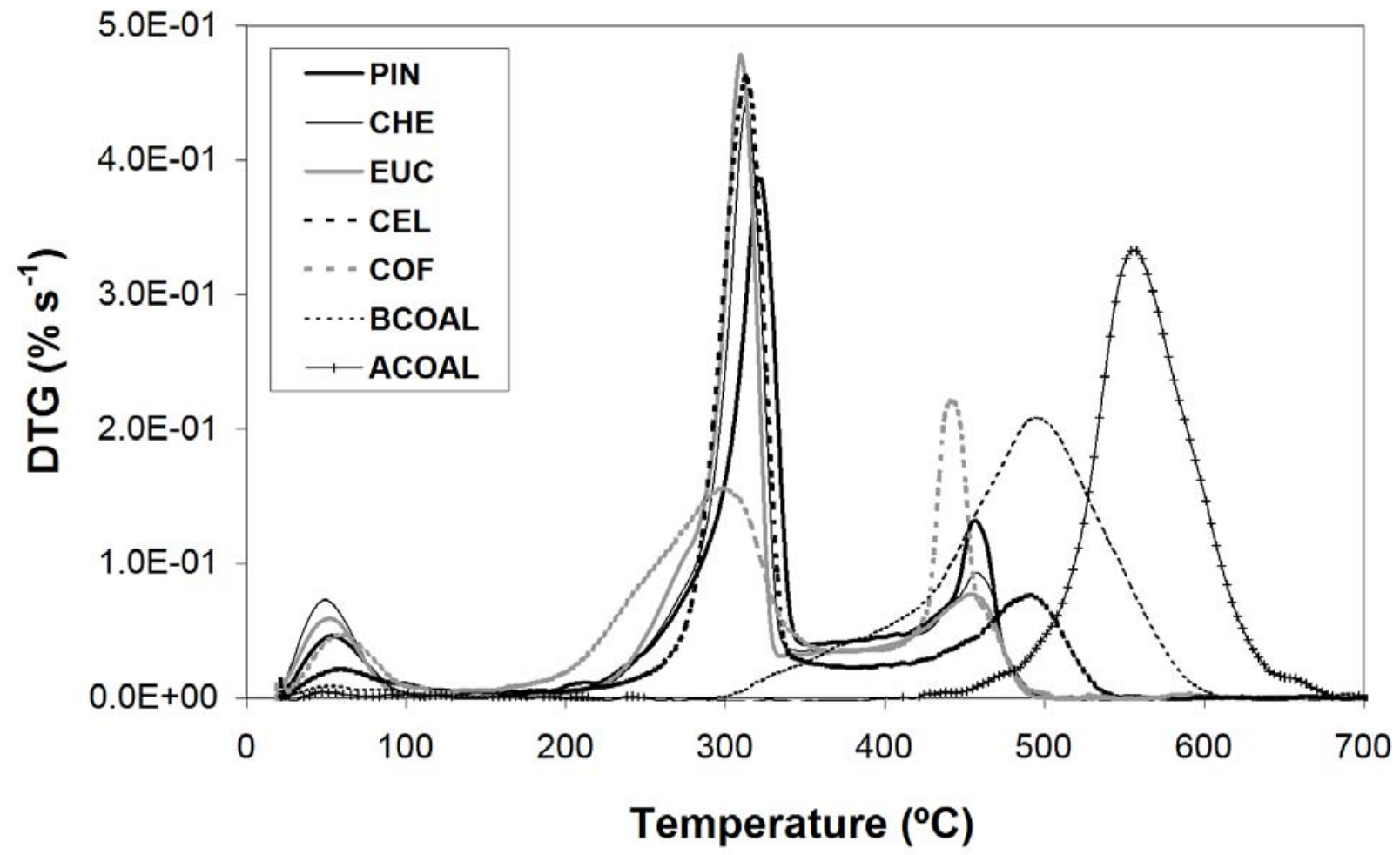

Fig. 3. 

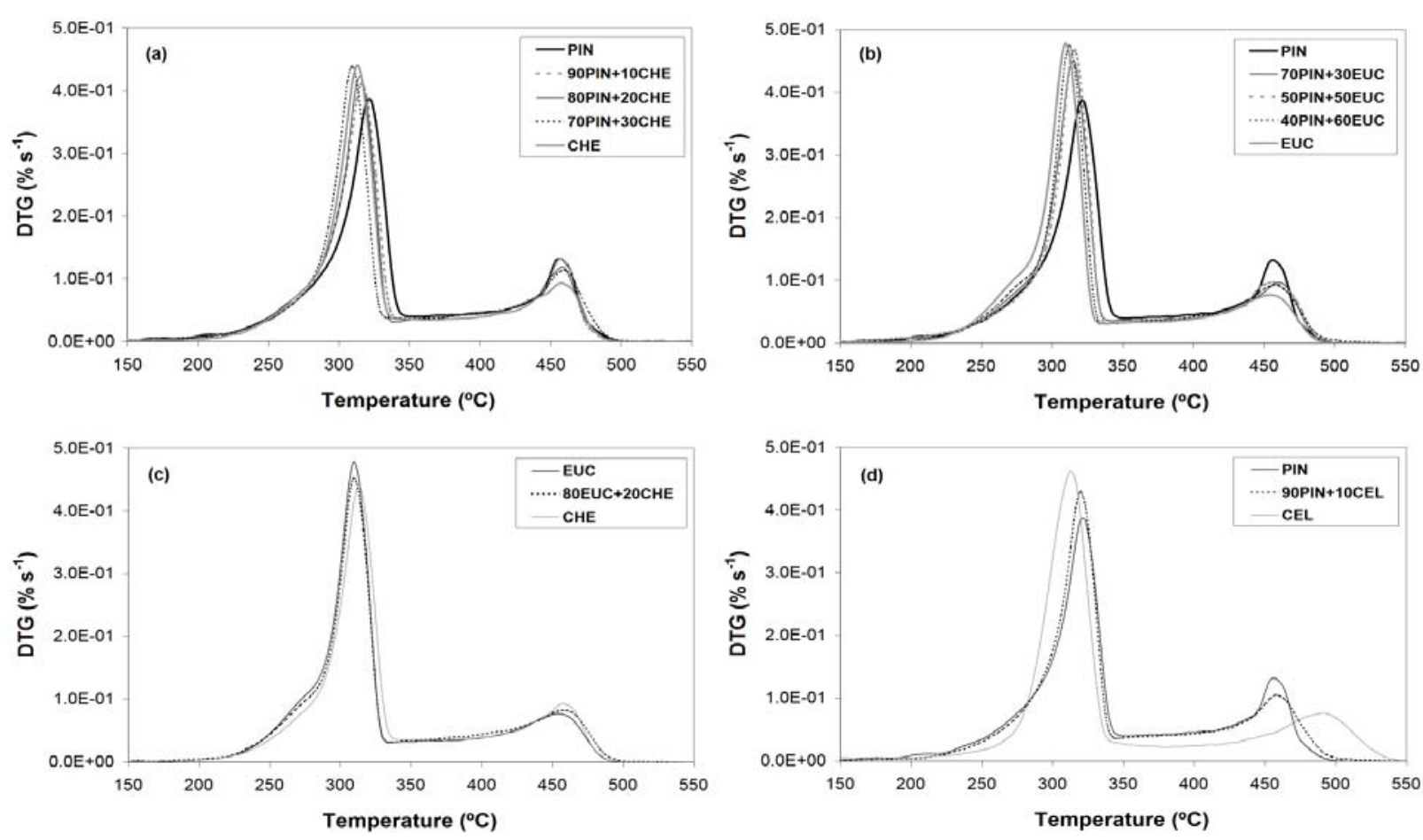

Fig. 4. 

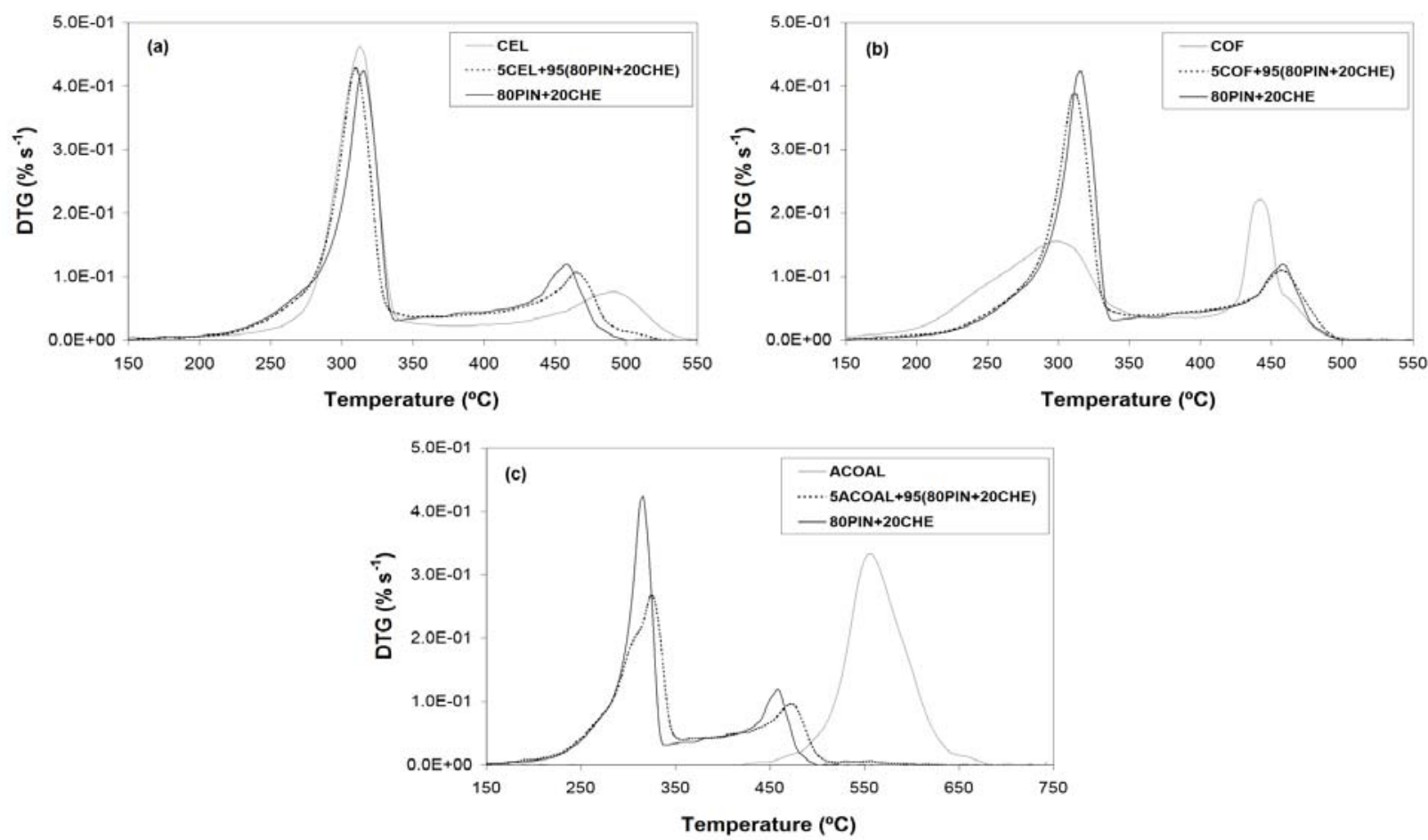

Fig. 5. 

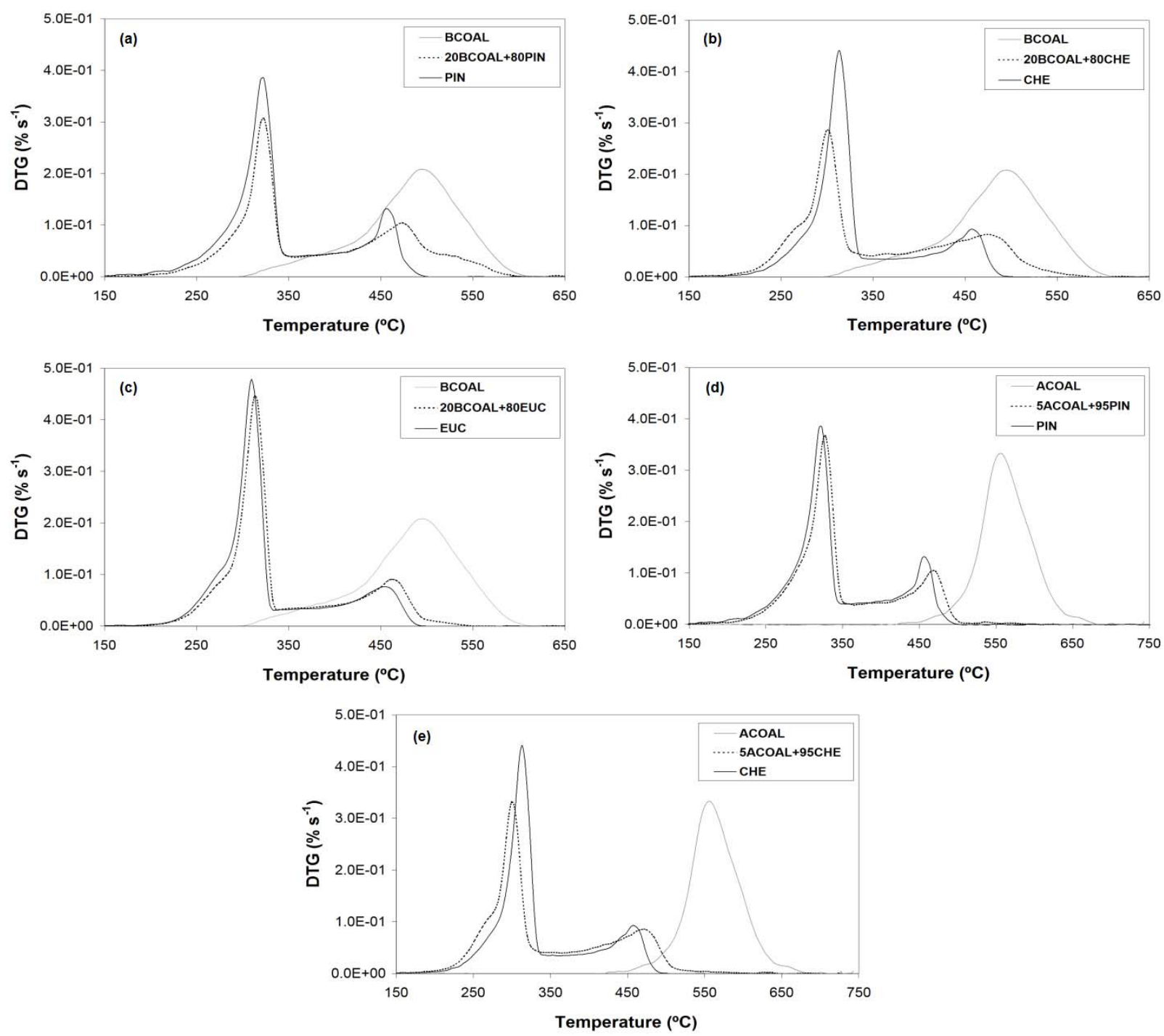

Fig. 6. 